\title{
Justicia y legitimidad en el Derecho de Gentes de Rawls
}

\author{
MARIANO C. MELERO DE LA TORRE \\ UNED, Madrid
}

RESUMEN. El propósito del presente trabajo consiste en mostrar las deficiencias del Derecho de Gentes de John Rawls, para luego determinar de otro modo el contenido de una teoría política internacional de cuño genuinamente liberal. Las modificaciones que aquí se proponen conducen a un modelo de justicia internacional que incluye la protección de los derechos básicos de todos los ciudadanos del mundo $\mathrm{y}$, restringido por esa estructura cosmopolita, el reconocimiento de los derechos de autodeterminación de las unidades políticas subglobales. En definitiva, la propuesta es un ideal de sociedad planetaria gobernada por un sistema de Derecho internacional más exigente que los principios de la difusa Sociedad de Pueblos «razonables».

\section{La dualidad de la justicia}

La tesis más sorprendente del Derecho de Gentes de John Rawls, y que han destacado con mayor énfasis sus críticos liberales, es aquella que sostiene lo que podríamos denominar «la dualidad de la justicia» '. Es decir, que existen profundas diferencias entre los principios de justicia igualitarios de una democracia liberal y los que pueden ser impuestos legítimamente en un
ABSTRACT. The present paper pretends to show the faults of Rawls's Law of Peoples, and then to establish in different terms the content of an international political theory with genuinely liberal spirit. The various changes here proposed lead to a model of international justice that includes both the protection all over the world of citizens' basic rights and, restricted by this cosmopolitan scheme, the recognition of subglobal political units with self-determination rights. In short, the proposal is an ideal of global community based on a federation that involve a system of International Law more demanding than the principles of the diffuse Society of «reasonable» Peoples.

sistema legal internacional. Este desdoblamiento se deriva, según se sugiere en esta obra, de las consideraciones de legitimidad que debemos tomar en cuenta al construir teorías razonables de justicia. Se supone que una aplicación adecuada de la noción de legitimidad hace que debamos considerar incorrecto cualquier intento de forzar en el Derecho internacional los principios de justicia liberales igualitarios, puesto que tales principios no pueden ser 
públicamente justificados en sociedades con culturas políticas no liberales. Y así, un orden legal internacional legítimo sólo puede requerir a los Estados no liberales que sean pacíficos en su política exterior y que respeten un sistema restringido de derechos humanos en su trato con sus ciudadanos -estos «derechos humanos básicos» incluyen únicamente el derecho a la vida y a la seguridad, la libertad de conciencia, la propiedad personal, la igualdad ante la ley y los derechos de asociación y de emigración ${ }^{2}$ - Si cumplen estas condiciones, los pueblos no liberales deben ser respetados como miembros plenos de la Sociedad de Pueblos bien ordenados. Pero, como es obvio, esta tesis implica consecuencias inaceptables desde un punto de vista liberal ${ }^{3}$.

A mi modo de ver, es importante tener en cuenta las consideraciones de legitimidad en una teoría de la justicia, pero ello no debería conducirnos a aceptar la dualidad de la justicia. La afirmación de que los principios políticos liberales (o la gama completa de los derechos humanos) contradicen las tradiciones culturales de los pueblos no liberales es a menudo una simple excusa de las élites dominantes de estos pueblos para seguir manteniendo sus privilegios de poder y riqueza. Aunque Rawls pretende basar su Derecho de Gentes en la «revolución jurídica» que ha supuesto el régimen internacional de los derechos humanos desde la Segunda Guerra Mundial, lo cierto es que su teoría exige unos requisitos mínimos de decencia política muy inferiores a dicho estándar de moralidad. Concretamente, los derechos humanos definidos en las convenciones internacionales incluyen, además de los «derechos humanos básicos», las libertades civiles y políticas que son familiares en una democracia liberal. Por supuesto, Rawls sólo considera legítimas las sociedades jerárquicas bien ordenadas, es decir, aquellas cuya estabilidad se garantiza mediante unos principios públicos de jus- ticia que, una vez implementados en las instituciones comunes, generan su propio apoyo. En una sociedad bien ordenada, liberal o jerárquica, el orden público se considera legítimo a los ojos de los miembros de esa sociedad. El problema es que si faltan las libertades individuales, no existe ninguna garantía de que dicha estabilidad se produzca «por las razones correctas». Un régimen perfeccionista suficientemente inteligente puede lograr a la larga un amplio apoyo popular, sustituyendo de forma gradual la imposición por la fuerza de sus principios discriminatorios mediante políticas efectivas de adoctrinamiento.

Sobre el trasfondo de las reformulaciones de Political Liberalism ${ }^{4}$, el Derecho de Gentes pretende extender el principio de tolerancia a los pueblos que son internamente no liberales. Esta estrategia puede resumirse más o menos así: del mismo modo que las sociedades liberales deben tolerar ad intra doctrinas comprensivas cuyas prácticas y tradiciones no se ajustan a los principios liberales - siempre y cuando dichas doctrinas respeten los derechos públicos de los individuos que se identifican con ellas y sean tolerantes con otras doctrinas comprehensivas-, las sociedades liberales también deben tolerar ad extra a los pueblos cuyas concepciones de la justicia no son liberales - siempre y cuando dichas concepciones respeten los «derechos humanos básicos» de sus miembros y sean tolerantes con otras concepciones de la justicia (principio de no expansionismo)-. Sin embargo, si Rawls no cree que exista ninguna razón para que una sociedad liberal acepte concepciones políticas no liberales dentro de ella, ¿por qué debería aceptar estas concepciones como razonables fuera de sus fronteras? $\mathrm{O}$ dicho de otra forma, si las cargas del juicio (o el desacuerdo razonable) no representan una razón suficiente para tolerar que las minorías étnicas y religiosas de una sociedad liberal restrinjan los dere- 
chos individuales de sus miembros, ¿sobre qué base deberíamos tolerar las prácticas injustas de los pueblos no liberales?

El Derecho de Gentes reproduce la tensión del liberalismo político entre la tolerancia hacia los grupos razonables no liberales y el compromiso con la libertad individual de los miembros de esos grupos. Pero en el caso nacional, la tolerancia encuentra sus límites en el consenso entretejido sobre la concepción política (liberal) de la justicia, cuyas raíces se encuentran en las ideas implícitas de una cultura política (democrática) común. En el caso internacional, sin embargo, la tolerancia parece exigir un compromiso de los principios que han de regir la política exterior liberal con objeto de acomodar la perspectiva de las sociedades no liberales. Aunque Rawls defiende esta relajación de los límites de la tolerancia como la forma correcta de extender los principios liberales a las relaciones internacionales, en la práctica significa modificar dichos principios ante la diversidad de culturas políticas. Es decir, implica tener en cuenta el punto de vista de las sociedades jerárquicas decentes, no para prescribir los principios de justicia que les serían aplicables, sino «para asegurarnos que los principios liberales de política exterior son también razonables desde la perspectiva no liberal decente» 5 . Así, en lugar de insistir en la idea de ciudadanos libres e iguales con determinados derechos básicos, Rawls busca una concepción alternativa de los derechos humanos que «no pueda ser rechazada como peculiarmente liberal o propia de nuestra tradición occidental» y que sería en tal sentido «políticamente neutral». De igual forma, prescinde de las características igualitarias de la justicia como equidad con la intención de alcanzar una descripción de la justicia que contenga la «mayor generalidad» requerida por el contexto internacional. En suma, puesto que «no puede exigirse razonablemente que todos los regímenes sean libe- rales», si una concepción política liberal insistiera en la adopción de sus principios para la justicia internacional, sería irrazonable, puesto que tal insistencia violaría «el propio principio de tolerancia del liberalismo respecto a otras formas razonables de ordenar la sociedad» 6 .

Como han señalado varios críticos liberales, esta modificación del liberalismo político encaminada a satisfacer las condiciones internacionales es un serio error. Así, Fernando Tesón ha afirmado que «una teoría política no puede sobrevivir si se enmiendan continuamente sus supuestos con la intención de obtener los resultados que no parecen ajustarse con la teoría en su forma original. Esto es simplemente una forma de inmunizar la teoría contra la refutación (moral)» ${ }^{7}$. En una vena parecida, Kok-Chor Tan ha calificado la justicia internacional de Rawls como «un proyecto de modus vivendi, encaminado a lograr un compromiso entre regímenes liberales y no liberales, antes que [un proyecto] para alcanzar la estabilidad con respecto a la justicia liberal» ${ }^{8}$. A pesar de las intenciones iniciales del filósofo de Harvard, su Sociedad de Pueblos razonables no está basada en un consenso en torno a las ideas liberales de justicia, sino en un modus vivendi entre diferentes modelos de sociedad. Con todo, aunque no hay duda respecto a la pertinencia de estas críticas, no creo que hagan completamente implausible la idea que preside la construcción rawlsiana. Esta idea no es otra que la de dejar abierta la posibilidad de que los pueblos con culturas políticas distintas a las «nuestras» encuentren su propio camino para respetar los ideales del constitucionalismo democrático. Por supuesto, como acabamos de ver, la sociedad jerárquica decente de Rawls es inadecuada desde el punto de vista de la democracia liberal, pero representa una forma de gobierno constitucional, y por tanto no debería ser equiparada con el despotismo o la tiranía. En este sentido, pare- 
ce que hay buenas razones para hablar de una genuina categoría de constitucionalismo no liberal, es decir, un régimen político con importantes controles sobre la autoridad política, que preserva los elementos básicos de la justicia natural (esto es, que los caos similares sean tratados de manera similar), y que ayuda de este modo a mantener la legitimidad del gobierno a los ojos de sus ciudadanos. Como Rawls mismo advierte, «no afirmo que [los pueblos decentes] sean razonables, sino que no son plenamente irrazonables; pienso que deberíamos reconocer un espacio entre lo plenamente irrazonable y lo plenamente razonable» ${ }^{9}$.

\section{El criterio de razonabilidad fundamental}

El problema es que Rawls incluye estas formas de mínima decencia política dentro de la teoría ideal del Derecho de Gentes, lo cual implica, como acabamos de ver, la exigencia de que los liberales se queden al margen y no hagan nada frente a las posibles violaciones de derechos de los gobiernos no liberales. Aunque no debemos negarnos a la posibilidad de que las sociedades jerárquicas decentes establezcan términos equitativos de cooperación, tampoco podemos ignorar el hecho de que estas sociedades incorporan con frecuencia profundas desigualdades sociales y económicas en sus estructuras básicas. El método que emplea Rawls para lograr un consenso político a nivel global - la búsqueda de un terreno común entre pueblos liberales y no liberales- elimina la justificación de cualquier intento de crítica de las «concepciones de la justicia basadas en el bien común» de las sociedades jerárquicas decentes. O dicho con otras palabras, nuestro filósofo parece suponer que, ante la diversidad de culturas políticas en el contexto internacional, los liberales deben ampliar su idea de pluralismo razonable hasta incluir concepciones políticas no liberales, y aceptar así como miembros de pleno derecho de la Sociedad de Pueblos las jerarquías decentes más desigualitarias, siempre que éstas sean compatibles con las condiciones del que podríamos denominar «criterio de razonabilidad fundamental» —es decir, el no expansionismo y el respeto a los derechos humanos básicos-. Estas condiciones legitiman, por ejemplo, órdenes sociales basados en doctrinas religiosas (o en cualquier otra clase de concepciones comprehensivas) que discriminan sistemáticamente a ciertos grupos sociales por razón de su género o de su adscripción étnica.

Negar toda validez a este criterio de razonabilidad fundamental sería tanto como asumir que cualquier argumento en favor de las sociedades jerárquicas será siempre tan defectuoso que ninguna desviación de los derechos liberales puede contar como razonable. Lo cual, como ya he señalado, me parece incorrecto. Ahora bien, parece evidente que el criterio fundamental de razonabilidad debería incluir restricciones mucho más severas sobre las desigualdades sociales. Las discriminaciones basadas en concepciones comprehensivas, cuando afectan profundamente a las oportunidades de las personas, no pueden quedar amparadas en una supuesta ampliación del pluralismo razonable ${ }^{10}$. La mayoría de los argumentos utilizados por los defensores de las desigualdades de género, raza, etnia o casta tienden a hacer generalizaciones eminentemente criticables desde cualquier mínimo estándar de argumentación racional. Sin embargo, la forma en la que entiende Rawls la tolerancia en el contexto internacional le impide ver la necesidad de juzgar la razonabilidad de las concepciones comprehensivas de los pueblos jerárquicos decentes - los argumentos, supuestos e inferencias que usan sus élites gobernantes para justificar las desigualdades - En definitiva, como ha observado Thomas McCarthy, lo que hace Rawls a nivel global es reemplazar tácita- 
mente el pluralismo razonable - cuyos límites vienen fijados por las ideas y valores implícitos y compartidos de la cultura política democrática - por el pluralismo de facto de doctrinas comprehensivas, restringido únicamente por los requisitos mínimos de su noción revisada de razonabilidad "'. Y así, mientras en el caso nacional lo razonable abarca únicamente los desacuerdos que caen dentro del alcance de las cargas del juicio y que pueden considerarse, por tanto, como el resultado del uso libre de la razón en condiciones democráticas, en el caso internacional lo razonable incluye todas las diferencias político-culturales, sin importar que sean debidas o no a cargas específicas de la razón.

De estas observaciones se deduce que, aun cuando creamos necesario preservar el principio de legitimidad de Rawls (el criterio de razonabilidad fundamental), no podemos aceptar las implicaciones que él cree que tiene para un orden legal internacional moralmente defendible. Más concretamente, resultan inaceptables las implicaciones regresivas que él pretende deducir de tal principio en lo concerniente a los derechos humanos ${ }^{12}$. Para hacer más claro lo que aquí se sugiere, nos centraremos en dos aspectos en los que el principio de legitimidad rawlsiano resulta del todo insatisfactorio: la tolerancia religiosa y la oportunidad del disenso individual.

Según Rawls, un pueblo no liberal puede ser razonable en la medida en que su doctrina religiosa oficial sea capaz de articular una concepción de la justicia, según su idea del bien común, que tome en consideración los intereses fundamentales de todos sus miembros. Dada esta especie de autolimitación de la religión oficial, los pueblos no liberales son capaces de tener una política no expansionista hacia el exterior, y de ofrecer un nivel suficiente de libertad de conciencia para asegurar la libertad de pensamiento y religión hacia el interior. Aunque sólo los miembros de la religión oficial pueden ocupar las principales instituciones del Estado, el resto de las religiones del país tienen garantizadas las condiciones cívicas y sociales que permiten su práctica en paz y sin miedo - en una situación denominada «libertad de conciencia, pero no libertad igual»-De De este modo, Rawls parece suponer que la cultura política de estas sociedades sólo permite garantizar la libertad religiosa como un derecho de grupo, es decir, como una tolerancia entre grupos. Sin embargo, es posible argumentar que la falta de protección de la libertad individual dentro de los grupos puede convertir a las sociedades jerárquicas en Estados despóticos. Según Rawls, «una concepción de la justicia basada en el bien común» debe otorgar a todos los miembros de la sociedad unos derechos y deberes básicos con independencia de su adscripción religiosa. Este mínimo estatus de ciudadanía, por el que todos los individuos se reconocen como «miembros responsables de la sociedad», no debería poder ser revocado por el hecho de poner en cuestión o abandonar el grupo de adscripción original. Si Rawls no añade esta condición en su principio de razonabilidad fundamental es porque presupone que en este tipo de sociedades nadie tiene aspiraciones liberales, o que, en el caso de tenerlas, es suficiente con que el Estado les garantice el derecho a emigrar ${ }^{13}$. Pero es dudoso que ésta sea una alternativa razonable a la falta de libertad de conciencia dentro de los grupos. Al margen de la cuestión de si el derecho a emigrar puede tener algún sentido relevante sin el correspondiente derecho a inmigrar - cuestión que Rawls despacha demasiado deprisa invocando otros derechos de igual naturaleza, como el derecho a casarse, a tener invitados en casa o a hacer una promesa-, está el asunto de si con esta actitud el Estado no está consintiendo que los grupos actúen tiránicamente con sus miembros, convirtiéndose él mismo en un Estado tiránico ${ }^{14}$. 
La posibilidad de que la sociedad en su conjunto acoja a aquellos ciudadanos que abandonan su grupo de adscripción no debería ser descartada en sociedades no liberales, donde las personas se ven a sî mismas, en primer lugar, como miembros de grupos culturales. De hecho, estas sociedades también constituyen, en sí mismas, grupos culturales. Los pueblos o naciones tienen, en la concepción rawlsiana, una cultura común de la que dependen los individuos «para encontrar su lugar en el mundo social» ${ }^{15}$. La concepción de la justicia basada en el bien común de un pueblo no liberal debería servir, por tanto, a pesar de su parcialidad, para poder integrar en la vida social a aquellos individuos que abandonan su grupo de adscripción original y no pueden, o no quieren, ingresar en otro. Pero para ello hace falta una condición ulterior. Esta posibilidad no podrá hacerse efectiva mientras la sociedad decente no permita un cierto grado de desacuerdo interno respecto a las interpretaciones de la cultura común. Cuanto más rígida sea dicha cultura, o cuanto más sistemáticamente reproduzca la religión oficial, menores serán las posibilidades de integración de los individuos procedentes de otras religiones. Como se sabe, la sociedad decente de Rawls incluye una jerarquía consultiva que permite que sean oídas «diferentes voces». Pero esta oportunidad sólo se otorga a los individuos como miembros de grupos, y «del modo apropiado según los valores religiosos y filosóficos de la sociedad tal y como se expresan en su idea del bien común» ${ }^{16}$. $\mathrm{La}$ cuestión es si la prohibición del disenso individual respecto de las prácticas e instituciones comunes, o frente a los procedimientos para manifestar las diferencias, no conduce al Estado decente a actuar tiránicamente. Rawls se desentiende de este asunto, pero si tenemos en cuenta su propio «hecho de la opresión» - es decir, el hecho de «que un entendimiento continuo y compartido sobre una doctrina com- prehensiva religiosa, filosófica o moral sólo puede ser mantenido mediante el uso opresivo del poder estatal» ${ }^{17}$-, deberíamos añadir la oportunidad del disenso individual como una condición de razonabilidad fundamental para cualquier esquema de cooperación mínimamente equitativo.

\section{Derechos humanos y derechos colectivos}

En mi opinión, Rawls confunde en su Derecho de Gentes dos problemas bien distintos. Cree que si definimos los principios de la justicia internacional sin tener en cuenta otras formas de cultura política nos vemos conducidos a un principio general de intervención que no respeta el legítimo derecho de autodeterminación de los pueblos. Pero una cosa es definir los principios que han de regir las relaciones internacionales desde un punto de vista liberal, y otra muy distinta establecer los medios legítimos para imponer esos principios a las naciones no liberales ${ }^{18}$. Al no distinguir claramente estas dos cuestiones, Rawls convierte su Derecho de Gentes en una acomodación de los principios liberales de justicia a la diversidad de culturas políticas. $\mathrm{Y}$ así, en lugar de fundar las relaciones internacionales, como era su propósito, en un consenso en torno a valores liberales, lo que hace en realidad es modificar esos valores con el fin de asegurar que dicho consenso pueda ser refrendado por algunos pueblos no liberales. El resultado es la tesis de la dualidad de la justicia, con todos los problemas que acabamos de ver.

La cuestión acerca de los principios de la justicia internacional hace referencia a la teoría ideal del Derecho de Gentes. Es decir, ¿bajo qué condiciones debemos pensar que los pueblos tienen derecho a ser respetados como fuentes autónomas de fines? ¿Cuál es el contenido moral del derecho de autonomía de los pueblos? Si no deseamos defender la tesis de la duali- 
dad de la justicia, deberíamos contestar a estas preguntas afirmando que, desde un punto de vista liberal, las condiciones de legitimidad de los pueblos son el control democrático del gobierno y el respeto a los derechos y libertades individuales. Estas dos condiciones cubren la gama completa de los derechos humanos, tal y como se recogen en la Declaración Universal de 1948. Con esta exigencia de justicia podemos mantener el principio de «igual libertad» del Derecho de Gentes de Rawls sin estrechar el horizonte normativo de los valores liberales. La autonomía de los pueblos y el deber consiguiente de no intervención son la cara externa de su legitimidad, pero siempre que ésta pueda ser descrita a través de un contrato hipotético por el que sus miembros «consienten» los términos de su asociación.

Los principios de la democracia liberal están en la base de la doctrina de los derechos humanos, la cual puede resumirse con el principio dworkiano de la «igual consideración y respeto" de los intereses de cada persona. Por este motivo, numerosos críticos del liberalismo han atacado esta doctrina señalando que no respeta adecuadamente la diversidad etnocultural. $\mathrm{La}$ fundamentación de los derechos humanos está, según argumentan estos críticos, culturalmente sesgada. Presupone una concepción de las personas como sujetos autónomos que resulta incompatible con aquellas culturas no occidentales que poseen una concepción más colectivista 0 comunitaria de la identidad humana. La oposición de Rawls contra el «liberalismo expansionista» se hace eco, como hemos visto, de estas críticas, rechazando incluso la posibilidad de extender a las culturas no occidentales la concepción «política» de la persona libre e igual que él mismo hace valer frente a los grupos religiosos y culturales no liberales dentro de los países democráticos. En definitiva, tanto el liberalismo político como el liberalismo comprehensivo consideran a las personas como poseedores de «los dos poderes morales» (la capacidad de autonomía individual y la de tener un sentido efectivo de la justicia), y su extensión universal equivaldría en ambos casos «a afirmar que todas las personas deben tener los derechos liberales iguales de los ciudadanos de una democracia constitucional» ${ }^{19}$. Como consecuencia, los críticos del liberalismo, secundados en este caso por Rawls, afirman que la doctrina de los derechos humanos sólo puede tener un verdadero alcance universal si debilita o atenúa su sesgo individualista y pone mayor énfasis en las partes más comunitaristas de la Declaración, especialmente en su artículo 29, según el cual «toda persona tiene deberes respecto a su comunidad, puesto que sólo en ella puede desarrollar libre y plenamente su personalidad». Es decir, que los derechos humanos deben ceder ante el derecho de autogobierno de los pueblos, el cual permite a los grupos nacionales no liberales usar el poder del Estado para restringir la libertad de sus propios miembros en nombre de la solidaridad de grupo. Por otra parte, desde una perspectiva histórica, el peso del colonialismo de los siglos XIX $\mathrm{y} \mathrm{XX}$ ha dejado claro que las formas dominantes de los ideales universales del liberalismo y la ilustración, «putativamente trascendentes, estaban en realidad construidas socialmente y estaban profundamente relacionadas con el poder y el interés» ${ }^{20}$. Hoy en día, según McCarthy, las tendencias recientes de la globalización neocolonial provocan, como reacción, «un asalto total al universalismo eurocéntrico, y junto a esto, la celebración de las diferencias culturales», de modo que las políticas de la identidad y de la diferencia adoptan típicamente «la forma de una oposición de lo particular a lo universal, de la multiplicidad real de culturas a la presunta unicidad de la razón, a menudo con el argumento de que los principios y las prácticas de la razón no pueden trascender las fronteras culturales» ${ }^{21}$. Como resulta- 
do, la autonomía de los pueblos se concibe como una defensa frente al modelo eurocéntrico de un nuevo orden mundial.

Pero esta crítica no acierta a describir correctamente las relaciones entre los derechos humanos y la diversidad cultural. La crítica del etnocentrismo parte del supuesto de que los derechos colectivos, como el de autogobierno, tienen un fundamento distinto al de los derechos humanos, y que por tanto pueden ser esgrimidos por las culturas no occidentales para la defensa de su cohesión social frente a los efectos corrosivos de los valores individualistas occidentales. Pero esto no es cierto. Que los derechos humanos conciban a las personas como sujetos morales autónomos no significa que favorezcan estilos de vida despegados de la vida comunitaria, o que menosprecian los intereses comunitarios cuando no pueden ser reducidos a los intereses de los individuos. Simplemente prohíben que los fines, tradiciones y prácticas comunitarias se sostengan con independencia de la voluntad de los individuos, o que el disenso intragrupal se suprima por la fuerza. Protegen el derecho de los individuos a definir por sí mismos los fines que desean perseguir en su vida. Esto sigue siendo verdad para aquellos derechos colectivos o de grupo, como el derecho a hablar la propia lengua o a practicar la propia religión, que representan condiciones esenciales para el ejercicio de los derechos individuales. Como ha señalado Michael Ignatieff: «El derecho a hablar una lengua de tu elección no significa gran cosa si la lengua ha muerto. Por esta razón, los derechos de grupo son necesarios para proteger los derechos individuales» ${ }^{22}$. La justificación última de los derechos de grupo no es la defensa del grupo como tal, sino la protección de los individuos que lo componen, por lo que el derecho colectivo a la lengua, por ejemplo, no ha de usarse para impedir a un individuo que aprenda una lengua distinta de la del grupo.
La aceptación del valor de la autonomía individual por parte de las culturas no occidentales no implica necesariamente su aniquilamiento como culturas distintas. De hecho, cuando las personas reclaman, en cualquier lugar del mundo, el amparo de los derechos humanos no pretenden amenazar con ello la supervivencia de su cultura. Como ha puesto de relieve Amy Gutmann, «las mujeres oprimidas desean que sus derechos como individuos sean asegurados dentro de su cultura, no a costa del exilio, o de la destrucción de lo que consideran valioso en ella» ${ }^{23}$. El respeto a los derechos humanos no es incompatible con ninguna cultura, aunque ese respeto requiera un cambio traumático en la moralidad pública de algunas de ellas, y más concretamente, en su concepción del individuo frente a la comunidad. En este sentido, los derechos humanos suponen una auténtica «revolución jurídica», dado que plantean una exigencia radical para todos los grupos culturales, esto es, que atiendan a los intereses de los individuos que los componen. Lo cual implica que estos grupos han de convertirse, en la medida de lo posible, en esquemas equitativos de cooperación entre libres e iguales. Querer proteger a las culturas de este cambio significa confundir la protección de la diversidad cultural con el mantenimiento de unas determinadas prácticas y tradiciones. La identidad y el bienestar de las personas están profundamente ligados a su propia cultura, pero la supervivencia de la comunidad cultural, de su herencia compartida, no se ve amenazada por la transformación de las normas y valores que en un momento dado pueden definir su carácter específico. Como ha explicado certeramente Will Kymlicka, «la comunidad cultural continúa existiendo aunque sus miembros sean libres para modificar el carácter de la cultura en el caso de que ya no encuentren valiosas sus formas tradicionales de vida» 24 . 
Pero si la protección de la diversidad cultural no está reñida, en su justificación, con la doctrina de los derechos humanos, entonces cabe la posibilidad defender ciertos derechos colectivos como un complemento necesario para asegurar la justicia en las relaciones intergrupales. La tendencia general de los movimientos en pro de los derechos humanos ha consistido, sin embargo, en negar la necesidad de derechos especiales para los miembros de grupos concretos, subsumiendo el problema de las minorías bajo el problema más genérico de asegurar los derechos individuales a todos los seres humanos, sin aludir a su pertenencia grupal. Bajo este enfoque, los grupos vulnerables pueden protegerse indirectamente garantizando los derechos civiles y políticos a todos los individuos, con independencia de su grupo de pertenencia. Sobre este punto existe uno de los desacuerdos más agudos e interesantes de nuestra cultura democrática reciente. Los defensores liberales de los derechos colectivos no ignoran, por supuesto, la importancia de los derechos individuales (de asociación, de culto, de expresión, de libre circulación, de organización política, etc.) para acomodar las diferencias culturales. Estos derechos permiten a los individuos formar y mantener una amplia gama de grupos culturales y religiosos. Pero estos autores subrayan que las pautas y procedimientos tradicionales vinculados a los derechos humanos son incapaces de resolver importantes cuestiones que tienen que ver con la justicia entre grupos, como son, por ejemplo, el trazado de fronteras, la selección del idioma oficial y las políticas de nacionalización ${ }^{25}$. La doctrina de los derechos humanos no sólo no ofrece ninguna respuesta a estas cuestiones, sino que a menudo ha servido para exacerbar aún más los conflictos intergrupales. Así, las reclamaciones por parte de las minorías nacionales de algún tipo de autonomía política o jurisdicción territorial — que les permita decidir por su cuenta la política de inmigración o el idioma oficial dentro de su territorio- son consideradas a menudo por los miembros de los grupos mayoritarios de los Estados multinacionales como una vulneración de los derechos humanos. En muchos casos estas reclamaciones se rechazan alegando que reflejan una perspectiva colectivista mucho más preocupada por el estatus de los grupos que por el bienestar de las personas. Pero este rechazo está basado, como hemos visto, en una comprensión equivocada de la fundamentación de estos derechos. Los derechos de grupo que aquí se contemplan no presuponen una justificación distinta de la que sostiene los derechos humanos. Su defensa no persigue la protección de las culturas frente a los efectos corrosivos de las libertades individuales. El objetivo, por el contrario, es tratar con igual consideración y respeto a los individuos como miembros de comunidades culturales distintas, para lo cual se pretende asegurar a todos la viabilidad de las culturas nacionales con las que se identifican y en donde forman y persiguen sus concepciones del bien.

Desde un punto de vista liberal, los derechos humanos constituyen las condiciones de legitimidad de la autodeterminación de los pueblos, $y$, por tanto, también de las minorías nacionales. En ambos casos, la promoción de las culturas no debe implicar la restricción de las libertades individuales de sus miembros. Pero el respeto de los derechos humanos no impide que el grupo mayoritario promueva su propia «construcción nacional» a expensas de los grupos minoritarios, actuando como si fuera la única cultura nacional existente dentro del territorio del Estado. Es más, la mayoría puede invocar la doctrina de los derechos humanos para rechazar las medidas que permiten a las minorías asegurar el pleno desarrollo de sus culturas. De ahí que, si no se desea que los derechos humanos puedan ser utilizados como un instrumento de subyugación o colonización, 
deben ser complementados con distintos derechos de grupo - derechos lingüísticos, de autogobierno, de representación, federalismo, etc. - Otro tanto puede decirse de los derechos «diferenciados» de los grupos inmigrantes -que tienden a fomentar la integración de estos grupos en el conjunto de la sociedad-y de los derechos especiales de representación - que tratan de reflejar la diversidad de la población en el proceso político-. El objetivo de estos derechos es transformar las formas de integración en la cultura común, de manera que, en palabras de Nancy Fraser. «la asimilación a las normas culturales mayoritarias o dominantes no sea por más tiempo el precio del igual respeto» 26 .

Por lo tanto, el cosmopolitismo implícito en un programa común de derechos humanos para todos los ciudadanos del mundo no necesita excluir el reconocimiento de los derechos colectivos de los grupos culturales. Al contrario, éstos representan el necesario complemento de aquéllos. Lo cual nos aproxima al modelo de «universalismo multicultural» defendido, entre otros, por McCarthy, según el cual «las políticas de la identidad y de la diferencia deben ir de la mano con las políticas de los derechos, la representación y la redistribución» ${ }^{27}$. Con todo, como ya advertimos más arriba, no existe un consenso en la cultura política democrática sobre cuándo las medidas gubernamentales que promueven una cultura violan o no los derechos humanos. Pero si en este punto nos dejamos aconsejar por los teóricos de la democracia deliberativa, y aceptamos el carácter razonable de nuestro desacuerdo sobre el contenido preciso de los derechos básicos, entonces deberíamos considerar igualmente razonable la discusión sobre cómo complementar esos derechos con las políticas del reconocimiento.

No obstante, nada de lo dicho hasta ahora tiene que ver con la parte no ideal del Derecho de Gentes. He argumentado que, desde una perspectiva liberal, los pueblos que no tratan a sus miembros como sujetos autónomos, o que no reconocen los derechos colectivos de sus minorías, actúan injustamente, por lo que, en principio, no es aplicable en su caso el deber de no intervención. Sin embargo; ¿bajo qué condiciones es legítimo intervenir en los asuntos internos de un pueblo para forzarle a respetar los derechos básicos de sus ciudadanos? ¿Qué tercera parte (de haber alguna) tiene autoridad para hacerlo? Creo que en este punto es absolutamente pertinente la distinción rawlsiana entre los pueblos «decentes», poseedores de una Constitución propia que impide el ejercicio arbitrario del poder político (mediante lo que aquí hemos denominado un «constitucionalismo no liberal»), y los pueblos «delincuentes» (outlaw peoples), que carecen de tales medidas constitucionales para limitar el poder de las élites dominantes. La falta de una Constitución interna hace que los pueblos traten de forma tiránica a sus miembros, y que no se comporten de manera razonable en sus relaciones internacionales. En estas circunstancias, los pueblos liberales (y decentes) tienen derecho a defenderse de las agresiones de los pueblos delincuentes, y a intervenir enérgicamente en ellos, mediante sanciones económicas o con el uso de la fuerza, cuando violan de forma grave y persistente los derechos humanos básicos de sus miembros - es decir, en los casos de esclavitud, genocidio o limpieza étnica-. Esto resulta del todo incontrovertible desde un punto de vista liberal, incluida la expresa referencia a la autoridad de las Naciones Unidas para tomar este tipo de decisiones ${ }^{28}$.

Lo que resulta más polémico es el principio de «igual libertad» que ha de guiar, según Rawls, la conducta de los pueblos liberales en su relación con los pueblos decentes. El mutuo respeto resultaría, sin duda, aplicable si se tratase simplemente de pueblos con una forma de 
organización política distinta de las democracias liberales, pero que mantienen el mismo compromiso con los principios básicos que presiden las constituciones democráticas. La idea de un constitucionalismo no liberal aceptable desde el punto de vista de los derechos humanos debe hacer referencia únicamente a las instituciones y procedimientos concretos por los que algunos pueblos tratan de imponer los principios de la justicia liberal a partir de su propia historia y de las tradiciones que conforman su vida pública. Sin embargo, sus principios básicos no pueden ser distintos de los de un régimen democrático constitucional. En mi opinión, rechazar la posibilidad de que estos principios puedan recibir una protección adecuada a través de unas instituciones diferentes a las que conocemos en los países occidentales evidencia un prejuicio etnocéntrico, una confianza implícita en la superioridad de «nuestras» instituciones.

Los pueblos decentes de Rawls, sin embargo, no comparten los principios básicos de los pueblos liberales. Por este motivo, su acomodación en un Derecho de Gentes liberal no puede pasar de ser un mero modus vivendi, es decir, el resultado de una negociación en la que es necesario modificar esos principios hasta hacerlos aceptables para ambas partes. Esto es perfectamente asumible, a mi juicio, desde el punto de vista de un Derecho de Gentes liberal, pero siempre que lo situemos en su parte no ideal, donde cabe aún preguntarse qué pueden hacer los liberales para tratar de extender sus convicciones políticas. En este sentido, creo que es posible apuntar tres clases de medidas. En primer lugar, los liberales deberían apoyar todas las iniciativas internas de los pueblos tendentes a liberalizar sus culturas. La visión monolítica de Rawls de las culturas políticas nacionales - «como si estuvieran hechas de una sola pieza» ${ }^{29}$ - convierte las relaciones entre los pueblos liberales y los no liberales en un enfrentamiento entre «nosotros» y «ellos», sin otra alternativa a la tolerancia que la mera imposición coactiva de las ideas liberales. Pero lo cierto es que en cualquier asociación política existen siempre minorías internas disidentes, inspiradas por las ideas liberales de libertad e igualdad. Según las expresivas palabras de Bruce Ackerman, «no hay ninguna sociedad islámica sin una mujer que insista en la igualdad de derechos; ninguna sociedad confuciana sin un hombre que niegue la necesidad de deferencia» ${ }^{30}$. La ayuda a estas minorías liberales internas favorece la universalización del liberalismo, sin que suponga coerción alguna. En segundo lugar, entre la tolerancia y la imposición también cabe la posibilidad de ofrecer incentivos en favor de las reformas liberales. Actualmente, el ingreso en la Unión Europea es un poderoso incentivo para impulsar este tipo de reformas en los antiguos países comunistas del este de Europa. De igual manera, las negociaciones y los tratados comerciales permiten a las democracias occidentales poder ejercer su influencia para promover la liberalización de las tradiciones culturales. Por último, los liberales pueden impulsar la creación de organismos internacionales para proteger los derechos humanos y los derechos de las minorías. Sin duda, ésta es la forma más imparcial de promover la doctrina liberal, pues exige que los pueblos liberales sometan igualmente sus asuntos internos a la revisión de estos mecanismos internacionales. Como ha señalado Ignatieff, «universalidad implica consistencia; resulta inconsistente imponer a otros Estados las restricciones de los derechos humanos internacionales a menos que aceptemos la jurisdicción de estos instrumentos sobre los nuestros» ${ }^{31}$. Aunque el Estado-nación siga siendo actualmente la mejor fuente de protección de los derechos, las convenciones y los tribunales internacionales proporcionan la garantía de un juicio imparcial para la crítica y revisión de las legislaciones nacionales. 


\section{El papel de la justicia distributiva global}

Tal como describe Rawls el objetivo general de la parte no ideal de su Derecho de Gentes, la intervención de los liberales en culturas políticas distintas a las suyas no debería traspasar el «deber de asistencia» a los pueblos más desfavorecidos. Este deber no proviene, según argumenta nuestro autor, de la aplicación de un principio de justicia distributiva global, sino del derecho que tienen todos los pueblos «a determinar por sí mismos el rumbo de su propio futuro» ${ }^{32}$. Su contenido incluye, como es obvio en un proyecto de justicia internacional cuyo principio fundamental es la «igual libertad» de las unidades políticas, únicamente aquellas medidas encaminadas a asegurar a todos los pueblos de la tierra las condiciones necesarias para la autonomía política. Lo cual significa, en el modelo rawlsiano, establecer en todas las sociedades el principio de razonabilidad fundamental - es decir, instaurar en todas ellas unas instituciones justas o decentes que les permitan ser miembros plenos de la Sociedad de Pueblos razonables-. En este sentido, el deber de asistencia se asemeja al principio del ahorro (real) justo dentro de las sociedades nacionales. En ambos casos, el propósito es «establecer y preservar instituciones básicas justas (o decentes), y no simplemente incrementar, ni mucho menos maximizar indefinidamente, el nivel medio de riqueza, o la riqueza de cualquier sociedad o de cualquier clase social en una sociedad» ${ }^{33}$. Nuestro deber «natural» de justicia, parece querer decir Rawls, no consiste únicamente en fomentar y mantener instituciones justas dentro de nuestra sociedad, sino también ayudar a que otros pueblos puedan desarrollar sus propios esquemas equitativos de cooperación.

Sin embargo, si se acepta la modificación que aquí se propone de los límites entre las partes ideal y no ideal de una teo- ría política normativa internacional, los pueblos liberales deberían impulsar las transformaciones culturales y políticas necesarias para lograr que se respeten por todo el mundo los principios de justicia de un régimen constitucional democrático. Teniendo en cuenta lo que llevamos dicho, la legitimidad del autogobierno de los pueblos debería basarse en el control democrático del gobierno, la protección de los derechos y libertades individuales y el respeto a los derechos de las minorías. Por tanto, si el objetivo general de la teoría no ideal es asistir a las sociedades desfavorecidas para establecer en ellas las condiciones que hacen posible una sociedad bien ordenada, entonces parece evidente que entre sus principales tareas debería estar la liberalización de sus culturas políticas públicas y la crítica de sus tradiciones. Rawls, en cambio, no aconseja este tipo de intervenciones, por entender que implican un expansionismo etnocéntrico de la cultura política democrática. Caracteriza las culturas políticas no razonables en términos tan «políticamente neutrales» como «gobiernos opresivos» y «élites corruptas», o por «la falta de preocupación por los derechos humanos (básicos)» ${ }^{34}$. En su opinión, esto permite promover condiciones político-culturales favorables para la autonomía política sin caer en el etnocentrismo. Sin embargo, reconoce que «la subyugación de la mujer» por ciertas doctrinas religiosas es una condición desfavorable que lo pueblos liberales deben ayudar a cambiar, y no está claro por qué razón no deberíamos decir otro tanto de la opresión de otros grupos identificados por la raza, la etnicidad, la clase, el estatus o cualquier otra marca ${ }^{35}$.

Además, el deber de asistencia implica una serie de medidas que tienen que ver directamente con la justicia distributiva internacional. La escasa preocupación de nuestro filósofo por las cuestiones distributivas a nivel global merece un especial comentario crítico. Resulta incomprensi- 
ble, cuando menos, que el autor de una de las concepciones igualitarias de la justicia más relevantes de la segunda mitad del siglo $\mathrm{XX}$ prescinda tan abiertamente de sus propios argumentos a la hora de formar su concepción de la justicia internacional. En concreto, ignora una de las correcciones fundamentales de su teoría de la justicia al liberalismo clásico: la conexión entre el «valor» de las libertades y las desigualdades socioeconómicas - el «valor» o «utilidad» para las personas de sus derechos y oportunidades depende de los recursos materiales a su disposición para ejercerlos o beneficiarse de ellos ${ }^{36}$ - . Para Rawls, el deber de asistencia internacional debe limitarse a favorecer la autonomía política de los pueblos, puesto que una yez establecidas las condiciones que posibilitan este objetivo, cualquier transferencia ulterior de recursos impediría que los pueblos asumieran la responsabilidad de sus decisiones políticas. Pero una cosa es exigir que los pueblos asuman la responsabilidad de sus decisiones, y otra muy distinta que tengan que asumir las consecuencias que se derivan de un mundo fuertemente interdependiente. Es más, resulta injusto pedir responsabilidades cuando se parte de unas relaciones económicas que no están basadas en la igualdad de oportunidades. El deber de asistencia debería incluir, por tanto, el establecimiento de un comercio internacional justo que no privilegie los intereses de los pueblos más desarrollados. Esto implica no sólo la reducción de las barreras internacionales al comercio, sino también un tratamiento especial diferenciado para los países pobres o en vías de desarrollo — con medidas tales como la protección de aquellos Estados cuya economía depende casi enteramente de la producción para un solo mercado-. En definitiva, se requieren mecanismos de dirección y redistribución que se ocupen de los efectos injustos de la globalización económica. Las desigualdades socioeconómicas entre las naciones afectan al «valor»
0 «utilidad» de las libertades civiles y políticas de sus ciudadanos, y si tales desequilibrios crecen desmesuradamente las libertades básicas de los menos aventajados pueden llegar a convertirse en «meramente formales». Por este motivo, la interdependencia económica internacional demanda un deber de asistencia mucho más exigente de lo que nuestro autor está dispuesto a admitir. Rawls no llega a esta conclusión porque previamente ha excluido de su Derecho de Gentes la universalización de los derechos civiles y políticos de una democracia liberal. Creo haber argumentado suficientemente en contra de esta tesis. Aun así, el deber de asistencia, tal y como él lo concibe, parece conducir a una conclusión similar, siempre y cuando apliquemos a nivel global los argumentos igualitarios que él mismo defiende en el caso nacional. Si el deber de asistencia tiene por objeto que cada sociedad devenga un «miembro libre y autosuficiente en la Sociedad de Pueblos», entonces será de obligada aplicación el primer principio de la justicia como equidad, que obliga a mantener el «valor equitativo de la libertades políticas» entre los participantes de cualquier esquema equitativo de cooperación, lo que implica un esfuerzo de redistribución a nivel global mucho mayor del que se sugiere en el Derecho de Gentes rawlsiano.

Por último, y dicho muy brevemente la defensa de los límites del Estado nacional no deberían servir de excusa para que los «ricos occidentales puedan solventar sus problemas de justicia señalando sencillamente que los extranjeros han nacido en otro sitio» ${ }^{37}$. A largo plazo, el deber de asistencia de Rawls, corregido en un sentido más genuinamente liberal, puede lograr un orden internacional en el que todos los pueblos tengan la oportunidad de estar bien ordenados, con una base de recursos y una cultura política que les permita alcanzar internamente los ideales de la justicia igualitaria. Sin embargo, mientras 
permanezcan las profundas desigualdades económicas internacionales, los pueblos más desarrollados tienen la obligación de abrir sus fronteras a los inmigrantes procedentes de los pueblos menos favorecidos. Esto no significa que, en las actuales circunstancias, los Estados liberales no puedan controlar los flujos migratorios. Incluso los defensores de las fronteras abiertas reconocen que estas restricciones pueden estar en parte justificadas por razones de orden público y porque sirven para asegurar la viabilidad de las instituciones liberales igualitarias dentro de los Estados ${ }^{38}$. Otros autores van incluso más allá, afirmando que pueden justificarse algunos límites a la inmigración con objeto de proteger la pertenencia cultural de las personas ${ }^{39}$. Pero, sean cuales fueren las razones por las que debemos presumir un derecho general de los Estados a controlar la inmigración, cabría argumentar que un país pierde este derecho si incumple sus obligaciones de asistencia con los países más pobres del mundo.

\section{A modo de conclusión}

El Derecho de Gentes de Rawls tiene quizá su principal virtud en el reconocimiento de la diversidad cultural y la autodeterminación de los pueblos. En línea con el proyecto de foedus pacificum kantiano, rechaza un Estado mundial por ser el origen más que probable o de un despotismo global o de un frágil imperio desgarrado por luchas civiles. Pero su propuesta de federación global, gobernada por unos principios que no incluyen ni los derechos democráticos ni las libertades civiles, parece una alternativa insuficiente para instaurar un Derecho internacional efectivo. Rawls parte de una imagen del mundo como una comunidad de Estados en gran parte autosuficientes que interactúan únicamente de forma marginal. Esta visión del mundo es la que predomina actualmente en la ONU, pero tiene ya poco que ver con el momento de globalización en el que vivimos. La presente situación internacional parece dar suficientes visos de madurez para establecer un orden cosmopolita en términos posnacionales. No sólo se está globalizando la economía de mercado y el consumismo. De su mano se extiende también imparablemente el consenso liberal, al menos en el plano de los principios generales. En este sentido, el nacionalismo democrático que subyace al Derecho de Gentes ha de ser corregido, aunque sin necesidad de apostar por la definitiva desaparición de los Estados nacionales. Es un hecho que cuanto más crecen las tendencias globalizadoras, mayores son las demandas de autonomía nacional y local. La corrección fundamental tendría que consistir en la aparición de una serie de instituciones y procedimientos globales encargados de elaborar, interpretar y hacer cumplir un sistema jurídico internacional que garantice el ejercicio de los derechos humanos a todos los ciudadanos del mundo, incluyendo los mecanismos de redistribución global necesarios para la consecución de este objetivo ${ }^{40}$.
1 «The Law of Peoples» apareció por primera vez en On Human Rights: The Oxford Amnesty Lectures, ed. S. Shute y S. Hurley, Nueva York, Basic Books, 1993, texto hoy incluido en Collected Papers, ed. S. Freeman, Cambridge, Mass., Harvard University Press, 1999. Una serie posterior de conferencias sobre el mismo tema fueron publicadas en The Law of Peo- ples, Cambridge, Mass., Harvard University Press, 1999. En estas notas nos referiremos a la primera versión mediante $C P$ y a la segunda con $L P$.

${ }^{2} C P$, p. $552 ; L P$, p. 79

En palabras de Allen Buchanan: «[La tesis de la dualidad de la justicia] significa que incluso los Estados que impiden a las mujeres o a los miembros de 
una determinada minoría étnica obtener educación, votar u ocupar cargos públicos, han de ser considerados como plenamente legítimos en tanto que no amenacen la seguridad física de tales personas, les ofrezcan un mínimo de bienes materiales para la subsistencia, no les persigan por su religión, y les permitan expresar sus concepciones en algún nivel apropiado de una jerarquía consultiva $y$ no sean expansionistas). Según Rawls, un Estado que usara los recursos públicos para mantener a una élite hereditaria en el lujo sería legítimo en tanto que todos estuvieran dotados con los medios de subsistencia.» Allen Buchanan, «Justice, Legitimacy and Human Rights", en The Idea of a Political Liberalism, ed. V. Davion y C. Wolf, Maryland, Rowman \& Littlefield Pub., 2000 , p. 80.

4 Nueva York, Columbia University Press, 1993.

${ }^{5} L P$, p. 58.

${ }^{\circ} C P$, pp. 552,537 y 563 .

7 Fernando Tesón, «The Rawlsian Theory of International Law», Ethics and International Affairs, n. 9 , 1995 , p. 85

8 Kok-Chor Tan, «Liberal Toleration in Rawls's Law of Peoples», Ethics, núm. 108, 1998, p. 285.

${ }^{2} L P$, p. 74

10 Como ha señalado Buchanan para el caso concreto de las discriminaciones por razón de género un reconocimiento adecuado de las cargas del juicio no impide que requiramos que se ofrezca una defensa positiva de estas desigualdades, ni que critiquemos tales defensas señalando que descansan en dudosas generalizaciones tales como que los «intereses esenciales》 de las mujeres difieren de los de los hombres o que las mujeres no son iguales a los hombres excepto en el mínimo sentido de que su bien ha de contar para algo. Véase Buchanan, op. cit., p. 84 .

1 Thomas McCarthy, «Unidad en la diferencia: Reflexiones sobre el derecho cosmopolita», Isegoría, núm. 16, 1997, p. 51.

12 Como ha indicado Carlos Thiebaut a este respecto: «Probablemente Rawls sólo esté sugiriendo que, de entrada, los derechos humanos son un requisito que habrá de plantearse a todas las naciones para el establecimiento de un sistema legal de relación entre ellas [...] La cuestion es si tal proceso de reconocimiento internacional no requiere e impulsa, con tal requerimiento, y de salida, formas políticas democráticas crecientemente reflexivas y deliberantes.» C. Thiebaut, «Democracia y diferencia: un aspecto del debate sobre el multiculturalismo», en Multiculturalismo y diferencia, Anales de la Cátedra Francisco Suárez, núm. 31, 1994, p. 59.

13 LP, p. 74.

14 En este sentido, Avishai Margalit ha observado que «cuando evaluamos el comportamiento de las instituciones sociales para determinar si son humillantes, debemos también incluir el comportamiento de las instituciones y organizaciones de los grupos abarcadores (encompassing groups) de la sociedad. S vemos que la naturaleza voluntaria de esos grupos es dudosa, y que no es fácil ser aceptado en otro grupo abarcador significativo, entonces el comportamiento humillante por parte de estas instituciones corrompe a la sociedad entera. En tal caso, una sociedad decente debe ofrecerse como una alternativa deseable a cualquier grupo abarcador que exista en su seno, de forma que los individuos puedan identificarse con ella y construir una forma de vida satisfactoria dentro de la sociedad general». A. Margalit, The Decent Society, Cambridge, Mass., Harvard University Press, 1996 pp. 278-279.

15 Political Liberalism, p. 222.

16 LP, p. 72

17 Political Liberalism, p. 37.

$18 \mathrm{La}$ distinción entre hacer un juicio y actuar según ese juicio ha sido señalada, para el caso de la extensión universal del liberalismo, por Joseph Raz (Ethics in the Public Domain, Oxford, Clarendon Press, 1994, p. 170), Will Kymlicka (Ciudadanía multicultural, Barcelona, Paidós, 1996, p. 227) y

K. Tan (op. cit., p. 285)

${ }_{19} L P$, p. 82

20 McCarthy, «Unidad...», op. cit., p. 39.

21 Ibid.

22 Michael Ignatieff, Human Rights as Politics and Idolatry, Princeton, Princeton University Press, 2001 p. 67.

${ }^{23}$ Amy Gutmann, «Introduction», en Ignatieff, op. cit., p. xxi.

${ }^{24}$ Kymlicka, Liberalism, Community and Culture, Oxford, Clarendon Press, 1989, p. 167

25 Véase Kymlicka, Politics in the Vernacular Oxford, Oxford University Press, 2001, pp. 71-82.

${ }^{26}$ Nancy Fraser, «Social Justice in the Age of Identity Politics: Redistribution, Recognition, and Participation», en N. Fraser y A. Honneth, Redistribution or Recognition?, Nueva York, Verso, 2003, p. 7.

${ }_{27}$ McCarthy, «Unidad...», op. cit., p. 55.

28 LP, p. 93.

29 McCarthy, «On the Idea of a Reasonable Law of Peoples», en J. Bohman y M. Lutz-Bachmann (eds.) Perpetual Peace, Cambridge, Mass., The MIT Press, 1997, p. 213.

30 Bruce Ackermann, «Political Liberalisms», The Journal of Philosophy, vol. 91, 1994, p. 382.

${ }^{31}$ Ignatieff, op. cit., p. 36.

$32 L P$, p. 118

${ }_{33} L P$, p. 107

${ }^{34} C P$, pp. 111 y 559

35 Véase McCarthy, «On the Idea of a Reasonable...» op. cit., p. 212.

36 Political Liberalism, p. 325

37 Ackerman, op. cit., p. 379

38 Joseph H. Carens, «Migration and morality: A liberal egalitarian perspective», en B. Barry y R. E. 
Goodin (eds.), Free Movement, Pennsylvania, The

Pennsylvania State University Press, 1992, p. 30.

40 Agradezco a Miguel Ángel Quintana Paz la lectura y discusión de una primera versión de este 175. 